\title{
UM ESTUDO SOBRE FIGURAS PLANAS E POLIEDROS COM O USO DO SOFTWARE GEOGEBRA: VIVÊNCIAS ACADÊMICAS NO PROJETO PIBID
}

\author{
Anderson de Oliveira Romeu ${ }^{1}$ \\ Elisa Netto Zanette ${ }^{2}$
}

\section{INTRODUÇÃO}

O estudo sobre a utilização de softwares matemáticos e outras Tecnologias da Informação e Comunicação (TIC) na Educação Matemática integra o programa de uma das disciplinas do Curso de Matemática - Licenciatura da Universidade do Extremo Sul Catarinense (UNESC). Integra também, uma das linhas de estudo dos acadêmicos que participam do Programa Institucional de Bolsa de Iniciação a Docência (PIBID) da UNESC, Subprojeto Matemática. O PIBID é uma Politica Pública, proposta pelo Governo Federal com a finalidade de atender a formação inicial à docência.

A participação no projeto PIBID, um espaço privilegiado de aprendizagem da docência, despertou inúmeras inquietações que impulsionam a continuar estudando sobre metodologias que envolvem o uso de softwares. No contexto matemático, o software GeoGebra, possibilita a representação e análise de diferentes entes geométricos, contribuindo para a elaboração dos seus conceitos. Pode-se utilizar de várias representações de um mesmo objeto matemático, potencializando o ensino e a aprendizagem dos conteúdos. Com interface, algébrica e geométrica, as construções em 2D e/ou 3D, ampliam a percepção espacial das formas geométricas.

A partir deste contexto, definiu-se como objetivo da pesquisa, investigar as possibilidades de uso e contribuição do software GeoGebrapara a elaboração dos conceitos de figuras planas e poliedros, como ação de aprendizagem a docência. $A$ vivência acadêmica pibidiana, na ótica dos pesquisadores, possibilitou experenciar

\footnotetext{
${ }^{1}$ Universidade do Extremo Sul Catarinense UNESC, acadêmico, anderson pop star@yahoo.com.br

${ }^{2}$ Universidade do Extremo Sul Catarinense UNESC, docente, enz@unesc.net
} 
atividades matemáticas, na forma de oficina, com acadêmicos do curso e com alunos de uma turma da Educação Básica, integrante do PIBID.

\section{METODOLOGIA}

A pesquisa em desenvolvimento iniciou em 2015. É bibliográfica e contempla as abordagens quali-quantitativa de coleta e análise de dados. A pesquisa qualitativa possibilita a compreensão com maior profundidade dos dados, a dispersão, a riqueza interpretativa, a contextualização do ambiente, os detalhes e as experiências únicas, como citam Sampieri, Collado e Lucio (2006).

A fundamentação teórica baseou-se em livros, artigos, portais educacionais e outros referenciais que contemplam os temas de estudo. O diário de bordo foi o principal instrumento de coleta de dados.

Participaram da pesquisa, acadêmicos do subprojeto PIBID-Matemática e alunos da $8^{a}$ série da Educação Básica da E.M.E.I.E.F. Serafina Milioli Pescador, localizada em Criciúma (SC) e integrante do projeto no ano de 2015, com o acompanhamento da professora supervisora na escola.O processo de exploração do software e de materiais didáticos com alunos foi promovido em dois momentos: numa oficina, no Laboratório de Informática da UNESC, no IV Seminário Institucional PIBID,com os acadêmicos do subprojeto. Objetivou a socialização da proposta de aula. Na escola a oficina foi desenvolvida no período matutino, com carga horária de 04h/a, organizada em dois espaços distintos: sala de aula e sala informatizada.

$\mathrm{Na}$ escola, as ações contaram com a atuação de sete pibidianos, organizados em dois grupos, com acompanhamento do professor supervisor e coordenadores de área do subprojeto. As atividades basearam-se na definição e construção de polígonos e poliedros em material de apoio e no software GeoGebra, enfatizando as relações entre seus elementos.Como material de apoio, utilizaram-se folhas de cartolina com desenho dos sólidos planificados, jujubas e palitos. A opção pelo software GeoGebra foi motivada por este se alinhar com os objetivos do estudo, por ter recursos de geometria dinâmica, ser multiplataforma, gratuito e de uso livre, possibilitando a utilização nas escolas, pelos alunos e professores.

As ações semanais (04 h/a) na escola em 2015 contemplaram atividades de observação de sala de aula, apoio aos discentes e a docente supervisora de Matemática. Neste período, os pibidianos familiarizaram-se com a escola, com os 
alunos das turmas de $8^{\circ}$ ano e com a atuação da professora supervisora. A proposição da oficina e do tema ocorreu naturalmente pela verificação da necessidade de estudo da geometria e pela importância da vivência acadêmica pibidiana, em experenciar atividades matemáticas em sala de aula.

\section{O PROCESSO DE APRENDIZAGEM À DOCÊNCIA NO CONTEXTO DO PIBID}

As Instituições de Ensino Superior (IES) tem se deparado com um cenário cada vez mais complexo de formação de professores, segundo Tinti (2012). A minimização de parte desses problemas está relacionada a formação continuada dos docentes em exercício e a potencialização da aprendizagem da docência, no processo de formação acadêmica dos licenciandos. Nesse enfoque, o programa PIBID integra as políticas docentes voltadas à formação inicial de professores, desenvolvida em âmbito federal. Como um programa nacional de fomento a iniciação à docência, é uma iniciativa para o aperfeiçoamento e a valorização da formação de professores para a educação básica. O programa concede bolsas de estudo aos alunos de licenciatura participantes dos projetos, desenvolvidos por IES, em parceria com escolas de educação básica da rede pública de ensino.

O programa PIBID tem por objetivos, segundo a CAPES (2008): Incentivar a formação de docentes em nível superior para a educação básica; Contribuir para a valorização do magistério; Elevar a qualidade da formação inicial de professores nos cursos de licenciatura, promovendo a integração entre educação superior e educação básica; Inserir os licenciandos no cotidiano de escolas da rede pública de educação, proporcionando-Ihes oportunidades de criação e participação em experiências metodológicas, tecnológicas e práticas docentes de caráter inovador e interdisciplinar que busquem a superação de problemas identificados no processo de ensino-aprendizagem; Incentivar escolas públicas de educação básica, mobilizando seus professores como co-formadores dos futuros docentes e tornandoas protagonistas nos processos de formação inicial para o magistério; e, contribuir para a articulação entre teoria e prática necessárias à formação dos docentes, elevando a qualidade das ações acadêmicas nos cursos de licenciatura.

Tinti (2012, p.47) destaca as potencialidades do projeto ao propiciar uma parceria efetiva entre IES e escolas. Esta parceria pode potencializar a formação inicial do professor de Matemática, uma vez que "concebe a inserção do licenciando 
na realidade escolar, de forma a familiarizá-lo com a cultura escolar; com as práticas educativas e com os principais desafios enfrentados pelos educadores no contexto educacional atual". Entretanto, afirma que há um equívoco conceitual na denominação do projeto, considerando que os bolsistas de iniciação a docência não são professores no início de seu efetivo exercício profissional.

Carvalho (2011, p.7) reflete sobre as contribuições nas relações estabelecidas com a interação e troca de experiências entre os professores supervisores que estão atuando na sala de aula e os pibidianos, enquanto licenciandos em formação:

\footnotetext{
Aliar os dois grupos de profissionais, alunos discentes bolsistas e professores supervisores das escolas públicas, formação inicial e continuada, engendra uma influência profícua no ambiente escolar, promovendo elevação da qualidade de ensino, aperfeiçoamento de técnicas didáticas e pedagógicas e sustentação de saberes pautados em estudo e conhecimento adquirido ao longo do processo colaborativo.
}

Concebe-se que, a participação dos acadêmicos licenciados no projeto PIBID justifica-se pela observação e experienciação da ação docente no contexto escolar, seu futuro espaço de trabalho. Na multiplicidade de saberes necessários para a atuação profissional inserem-se os saberes de domínio do conteúdo matemático e os saberes docentes citados por Tardif (2008) como os saberes experienciais. São inerentes à prática pedagógica, desenvolvidos na atuação e formação do professor, embasados nas mais diversas atividades e incorporados sob a forma de conhecimento, habilidades e competências. Além disso, é relevante, reconhecer os saberes dos alunos. No processo de ensino e aprendizagem, segundo Freire (1996, p.23), "Quem ensina aprende ao ensinar e quem aprende ensina ao aprender".

\section{A EDUCAÇÃO MATEMÁTICA E AS TECNOLOGIAS APLICÁVEIS A EDUCAÇÃO}

Para Novoa (2009) os desafios colocados pelas novas tecnologias revolucionaram o dia-a-dia das sociedades e das escolas e interferem diretamente nas ações didático-pedagógicas. Evidenciam-se as mídias informáticas como recursos e linguagens das atuais gerações. Podem contribuir nos processos pedagógicos em Matemática, na superação das dificuldades associadas à 
complexidade matemática, de compreensão das suas representações (WEISS; CRUZ, 2001). Sobre isso, Castells (2001) afirma que, faz-se necessário a aquisição de uma capacidade intelectual de aprendizagem e de desenvolvimento.

A utilização de recursos e metodologias diferenciadas e inovadoras no ensino da geometria pode contribuir para a superação das dificuldades dos alunos. Atividades mediadas por softwares geométricos são relevantes para a consolidação de alguns conceitos, por oportunizar ao aluno a validação de suas hipóteses e conjecturar sobre possíveis soluções (PEREIRA, 2012). O uso de softwares educacionais, como exemplo, o GeoGebra tem se tornado uma realidade nos últimos anos. Para Nascimento (2012) destaca-se em real importância para o desenvolvimento do processo de ensino e aprendizagem de matemática.

O software GeoGebra, em estudo, é um aplicativo gratuito, de matemática dinâmica, multiplataforma, disponível na rede Internet e pode ser utilizado online (UFF, 2014). Com duas perspectivas de interface, algébrica e geométrica, permite o desenvolvimento de atividades com a utilização de várias representações de um mesmo objeto matemático, potencializando o ensino e a aprendizagem de conteúdos em Geometria (MORAIS, 2012).

\section{A EDUCAÇÃO MATEMÁTICA E O ESTUDO DA GEOMETRIA}

Historicamente, a geometria foi o primeiro ramo da matemática a se organizar logicamente, segundo Usiskin (1994, p.34). Para Lorenzato (1995) a geometria tem uma função essencial na formação dos indivíduos ao possibilitar uma interpretação mais completa do mundo, uma comunicação mais abrangente das ideias e uma visão mais equilibrada da Matemática.

Usiskin (1994) situa a importância do estudo da geometria em quatro dimensões principais: medida-visualização; mundo real-físico; representação; e, suporte matemático. Na dimensão medida-visualização, exemplifica as atividades escolares em que o aluno desenha círculos, retângulos, retas paralelas, entre outros. Na dimensão mundo real-físico exemplifica pela observação da regularidade dos hexágonos numa colmeia natural, num quadro ou numa escultura, ou pelo carpinteiro na produção de um móvel que faz medições e procedimentos empíricos, sem necessariamente dominar a geometria. 
$\mathrm{Na}$ dimensão representação,Usiskin (1994, p.33) situa "a geometria como veículo para representar conceitos matemáticos, ou outros, cuja origem não é visual ou física". São as representações geométricas de ideias não geométricas como, por exemplo: a reta numerada que descreve o conjunto dos números reais; os gráficos diversos com informações numéricas; em cálculo, a área como uma ilustração inestimável do que se entendo por cálculo de uma integral. Na dimensão suporte matemático, situa a geometria como exemplo de um sistema matemático, por possibilitar justificar, discutir lógica, dedução e escrever demonstrações.

Para Usiskin (1994, p.36) a melhora do processo de ensino e aprendizagem em geometria, requer um número maior de professores bem preparados e alunos motivados em estudar geometria. Jardinetti (1996) cita que, as dificuldades de apropriação dos conceitos matemáticos tem relação também com a visão de muitos professores e alunos como uma disciplina difícil, por suas abstrações. Os procedimentos matemáticos da escola parecem muito diferentes dos utilizados no cotidiano, o que dificulta a compreensão da relação entre o que se estuda na escola e o que se aprende fora dela.

Micotti (1999) e Duval (2003) afirmam que a complexidade matemática, o caráter abstrato dos conceitos, situa-se na compreensão de suas representações semióticas, próprias da linguagem matemática. No contexto da Geometria Usiskin (1994, p.36) propõe o aperfeiçoamento do currículo e metodologias matemáticas que promovam a conceituação da geometria envolvendo as quatro dimensões de compreensão. Para o autor, a geometria "é importante demais no mundo real e na matemática para ser apenas um adorno na escola elementar ou um território de apenas metade dos alunos da escola secundária".

\section{VIVÊNCIAS ACADÊMICAS PIBIDIANAS NO ESTUDO DE FIGURAS PLANAS E POLIEDROS COM O USO DO GEOGEBRA: RESULTADOS E DISCUSSÕES}

A Unesc participa do projeto PIBID desde 2012, com alguns de seus cursos de licenciatura, incluindo o curso de Matemática. Nosubprojeto PIBID Matemática, participaram em 2015, três escolas públicas, três professores supervisores, dois professores coordenadores e vinte e três acadêmicos bolsistas.

Os subprojetos na UNESC devem promover a inserção dos acadêmicos no contexto das escolas públicas, desde o início da sua formação, para que 
desenvolvam atividades didático-pedagógicas, sob a orientação de um docente da licenciatura e de um professor da escola. Constitui-se como um espaço de promoção com qualidade de um ambiente de formação inicial e continuada da atividade docente na educação básica (UNESC, 2015).

Como resultado da pesquisa bibliográfica verificou-se que o uso do GeoGebra pode contribuir na elaboração de diversos conceitos geométricos e algébricos. Isso ocorre quando os estudantes tem a oportunidade de testar propriedades e teoremas, validar suas hipóteses. O recurso de movimento de figuras em todas as direções avançando e retrocedendo, permite a análise e comparação nos processos de construção dos objetos em estudo. A experimentação do software e de materiais didáticos relacionados ao conceito de geometria plana e espacial, em atividade de oficina com os acadêmicos do subprojeto PIBID-Matemática, mostrouse como uma possibilidade pedagógica de uso com os alunos nas escolas.

Parte-se do pressuposto que, no processo de ensino e aprendizagem, o aluno, sujeito em formação, é o ponto de partida, compreendido como ser social e histórico de direito subjetivo à aprendizagem e ao desenvolvimento. Sujeito que, "nas experiências de vida e nas relações com outros sujeitos, com a natureza e com as estruturas e instituições sociais, faz apropriações de mundo mediadas por diferentes linguagens" como consta na Proposta Curricular de Santa Catarina (SC, 2014, p.26). Cita como aporte teórico-epistemológico nas escolas estaduais, a perspectiva histórico-cultural que oferece um arcabouço dos mais amplos para a compreensão da Formação Integral e para a reflexão sobre ela. O mesmo aporte integra a Proposta Curricular do Município de Criciúma (SC).

A importância da vivência acadêmica pibidiana situa-se também na possibilidade de experenciar atividades matemáticas em sala de aula, simulando a prática futura de professor. Como afirma Tinti (2012), ao experenciar o processo de iniciação a docência, possibilita ao pibidiano desencadear reflexões sobre o futuro/possível ambiente de trabalho, contribuindo dessa forma para a superação de possíveis pré-conceitos sobre o sistema público de ensino. Para o autor, a vivência no PIBID pode contribuir na minimização do "choque de realidade" nos primeiros anos da profissão ao possibilitar vivenciar muitos dos dilemas emergentes no cotidiano escolar. Além disso, pode tornar a carreira docente mais atrativa para os alunos que cursam licenciatura. 
Segundo Carvalho (2011, p.7), aproximar o futuro professor da realidade da prática de regência é impactante em sua formação, pois situa de modo mais significativo os contextos envolvidos na sua formação acadêmica, quer sejam nos conhecimentos específicos relacionados aos tópicos de Matemática, quer sejam nas atividades de cunho pedagógico.Assim, a atividade desenvolvida na forma de oficinas, integrou as ações previstas enquanto acadêmico pibidiano no processo de iniciação a docência. Inicialmente, elaborou-se o planejamento da oficina na escola com o acompanhamento da professora da disciplina e supervisora na escola, no projeto PIBID. Esse planejamento inclui os objetivos, os conteúdos, as atividades, os recursos utilizados e os resultados esperados.

Em consenso com a professora supervisora, definiu-se como tema de estudo, as figuras planas e os sólidos geométricos com foco na construção e identificação de poliedros e figuras planas associadas. Estabeleceram-se como objetivos: Desenvolver nos alunos as capacidades de visualização e de representação geométrica; Promover o aprimoramento do raciocínio geométrico; Propiciar a visão da geometria de uma forma mais prática, mais visível, ao aluno; Reconhecer que os sólidos geométricos são formados pela composição de figuras planas; Exercitar a visão geométrica tridimensional; Identificar os componentes dos sólidos geométricos diferenciando poliedros de não-poliedro; Conceituar e diferencias os elementos dos diferentes sólidos; Utilizar os recursos do software GeoGebra em Laboratório de Informática na construção de sólidos geométricos.

O estudo dos poliedros e sua relação com as figuras planas, segundo Campos (2001), possibilita a compreensão tridimensional com o bidimensional, permitindo a comparação e a reflexão sobre suas formas, composição e decomposição. A interação entre os objetos geométricos de forma dinâmica mediada pelos softwares contribui com o processo de ensino e aprendizagem dos principais conceitos.

A atividade foi planejada em três etapas. Inicialmente, foi elaborada a fundamentação teórica sob o tema de estudo. Em seguida, foi elaborado o roteiro em forma de plano de aula para as oficinas. E, por último foram desenvolvidas as oficina. Optou-se por utilizar uma metodologia organizada numa sequência didática de forma que os alunos pudessem participar ativamente na elaboração dos conceitos. Durante as atividades, os pibidianos faziam questionamentos de forma a contribuir na análise dos elementos das figuras planas e espaciais. Utilizou-se como 
material e recurso de apoio: lápis, tesoura, cola, xerox das planificações, cartolina, palitos, jujubas e o software GeoGebra. O uso dos recursos selecionados objetivou também, motivá-los e mobilizá-los nas atividades. As atividades da oficina também foram organizadas em três etapas, não necessariamente sequenciais. Vivenciar o processo de iniciação a docência, possibilita ao pibidiano desencadear reflexões sobre o futuro ambiente de trabalho, como afirma Tinti (2012).

$\mathrm{Na}$ etapa I, foram apresentadas as principais definições das figuras planas, os elementos constituídos, os conceitos de perímetro, área e volume, usando o recurso do software PowerPoint e Datashow. Os tópicos trabalhados foram: Noções básicas de geometria plana e geometria espacial; Estudo dos Poliedros e Não-Poliedros (corpo redondo) - identificação, classificação e diferenciação; estudo do perímetro, área e volume dos prismas de base quadrada e retangular.

$\mathrm{Na}$ etapall, desenvolveu-se a atividade de construção dos sólidos geométricos a partir das planificações, disponibilizadas na forma impressa, em folhas de cartolina. Estas foram recortadas, dobradas e coladas nos locais indicados. No processo de debate sobre as figuras planas e os sólidos. Ao dar forma às planificações os alunos desenvolvem a visão espacial e refletindo sobre os diferentes sólidos e seus elementos, integrando a geometria plana e espacial. Para contribuir no processo de análise dos sólidos, os alunos foram convidados a dar forma aos poliedros e corpos redondos com o uso de palitos (representando as arestas) e jujubas (representando os vértices). Na montagem dos poliedros e corpos redondos planificados, ao trabalhar com as jujubas, ampliaram-se os debates, com a mediação dos pibidianos sobre o conceito e quantidade de vértices, faces e arestas, incluindo a aplicação da Relação de Euler para determinar a quantidade desses elementos nos sólidos construídos.

$\mathrm{Na}$ etapall, os alunos foram convidados a desenvolver as atividade com o uso do software GeoGebra em Laboratório de Informática. Utilizando os principais recursos do Geogebra, projetaram figuras planas e alguns sólidos. Além disso, efetuaram o cálculo de perímetro e área, das faces e bases de alguns sólidos.

$\mathrm{Na}$ metodologia prevista, as duas turmas de $8^{\text {a }}$ série foram acompanhadas por dois grupos de pibidianos. Enquanto uma das turmas participava dos debates teóricos do tema em sala de aula e após era orientada pelos ministrantes sobre as planificações e a montagem dos poliedros e corpos redondos, 
a outra turma desenvolvia as atividades em Laboratório de Informática com o uso do software GeoGebra. A dinâmica contemplou as mesmas atividades para as duas turmas.

A análise das formas planificadas e as representações espaciais, objetivou ampliar a percepção espacial, tornar mais significativa e presente a matemática na sala de aula, valorizando os saberes prévios dos alunos. Da mesma forma, o uso das jujubas na construção dos sólidos, propiciou a introdução do conceito de vértice, arestase faces dos poliedros. O cálculo do perímetro e área das figuras planas que formam as faces dos poliedros foi efetuado com o cubo e o paralelepípedo. Discutiu-se também sobre o volume e para isso, utilizou-se de cubos mágicos.

Durante a oficina, observou-se que, apesar dos alunos desconhecerem o software GeoGebra, o uso de seus recursos foram facilmente compreendidos. Ao interagir diretamente com 0 aplicativo nas atividades propostas, levantaram questionamentos, hipóteses e alternativas de solução que contribuíram no enriquecimento do ambiente de estudo. Evidenciou-se o interesse em saber mais sobre as figuras estudadas e as relações entre os seus elementos, relacionando-os com os objetos físicos (poliedros) construídos a partir das planificações. Como afirma Campos (2011), o estudo dos poliedros e sua relação com as figuras planas, possibilita a compreensão tridimensional com o bidimensional, permitindo a comparação e a reflexão sobre suas formas, composição e decomposição.

\section{CONCLUSÕES PRELIMINARES}

Os resultados da pesquisa mostram que há muitas produções científicas relacionadas a área em estudo. Na experimentação dos recursos do GeoGebra foram desenvolvidas atividades aplicáveis na Educação Básica relacionadas a figuras planas e sólidos geométricos. Verificou-se que é possível desenvolver diversas atividades de forma dinâmica,investigar alternativas na resolução de problemas e verificar se o resultado obtido está correto, com agilidade e rapidez.

O uso do GeoGebra possibilita elaborar conceitos com ênfase na análise do processo de construção dos elementos em estudo, o que pode contribuir significativamente para a melhoria do ensino e aprendizagem em Matemática. Ao manipular os objetos no GeoGebra e nos materiais de apoio, a percepção espacial 
dos alunos foi ampliada, considerando que estavam em contato direto com os objetos e/ou a simulação dos mesmos. Observou-se que os alunos compreenderam com facilidade os tópicos estudados quando utilizaram os materiais manipuláveis e o software GeoGebra, pelos questionamentos e soluções das atividades propostas.

O processo de vivência de iniciação a docência, proporcionou um espaço formativo diferenciado pela atuação na escola e na IES com os demais colegas pibidianos e professores. Possibilitou vivenciar dilemas e desafios inerentes a futura profissão, na explicitação dos conceitos matemáticos em estudo, na observação do processo de elaboração dos conceitos pelos alunos, pelos questionamentos, reflexões e atuação. Contribuiu para a aproximação da teoria vivenciada no curso de graduação e a prática experimental na escola.Conclui-se também, que é importante conhecer o contexto escolar, a dinâmica da escola, as rotinas do trabalho do professor, observado nas ações do docente supervisor, considerando ser este o principal espaço profissional de atuação futura dos licenciandos.

\section{REFERÊNCIAS}

CAMPOS, T. M. M. Transformando a prática das aulas de matemática. São Paulo: PROEM, 2001.

CAPES,Coordenação de Aperfeiçoamento de Pessoal de Nível Superiordo Ministério da Educação (MEC). Pibid: Programa Institucional de Bolsa de Iniciação à Docência. 2008. Disponível em: <http://capes.gov.br/educacao-basica/capespibid/pibid>Acesso em: 04 Abril2015.

CARVALHO, A.M.T. Impactos e desafios do projeto PIBID-Matemática da UEL. Anais do XIII CIAEM-IACME, Recife, 2011. Disponível em: < http://www.gente.eti.br/lematec/CDS/XIIICIAEM/artigos/1800.pdf > Acesso em: 10 Out 2015.

CASTELLS, M.A sociedade em rede. v.1. 5. ed. SP: Paz e Terra, 2001.

FREIRE, P.Pedagogia da autonomia: saberes necessários à prática educativa. 13.ed. Rio de Janeiro: Paz e Terra, 1996.

DUVAL, R. Registros de representações e funcionamento cognitivo da compreensão em matemática. In: MACHADO, S. D. A. (org.). Aprendizagem em matemática: registros de representação semiótica. Campinas: Papirus. 2003, p. 11-33. JARDINETTI, J.R.B. Abstrato e concreto no Ensino da Matemática: algumas reflexões. In: Bolema. Rio Claro, SP: UNESP, ano 11, n.12, 1996. p. 45-57. 
LORENZATO, S. Por que não ensinar Geometria? Educação Matemática em Revista. São Paulo/SP, v. 4, p. 3-13, 1995.

MICOTTI, M.C.O.O ensino e as propostas pedagógicas. In: BICUDO, M.A.V. Pesquisa em educação matemática: concepções e perspectivas. São Paulo: UNESP, 1999.

MORAIS, R. G. Geometria Dinâmica como alternativa metodológica para o ensino de geometria: experiência em um curso de Licenciatura em Matemática. 2012. Dissertação (Mestrado Profissional em Educação Matemática) - Universidade Severino Sombra, Vassouras/R.J., 2012.

NASCIMENTO, E.G.A.Avaliação do uso do software geogebra no ensino de geometria: reflexão da prática na escola. CLG. Uruguai. 2013. Disponível em: <http://www.geogebra.org.uy/2012/actas/procesadas1370724062/67.pdf> Acesso em: 05 Dez 2015.

NOVOA, Antonio. Professores: Imagens do futuro presente. Educa: Instituto de Educação. Universidade de Lisboa. Portugal, 2009.

PEREIRA, T.L.M. O uso do Software GeoGebra em uma Escola Pública: interações entre alunos e professor em atividades e tarefas de geometria para 0 ensino fundamental e médio 2012. (Dissertação de Mestrado). UFJF. Juiz de ForaMG. 2012.

SAMPIERI, R.H.; COLLADO, C.F.; LUCIO, P.B..Metodologia de Pesquisa. 3. ed. São Paulo: Macgraw-hill, 2006.

TARDIF, M.Saberes docentes e formação profissional. 9.ed. Petrópolis, RJ: Vozes, 2008.

TINTI, D.S. PIBID: um estudo sobre suas contribuições para o processo formativo de alunos de Licenciatura em Matemática da PUC-SP. Dissertação (Mestrado em Educação Matemática), Pós-Graduação em Educação Matemática, Pontifícia Universidade Católica de São Paulo, São Paulo, 2012.

UFF: Universidade Federal Fluminense. Conteúdos Digitais do Instituto GeoGebra do Rio de Janeiro. Disponívelem <http://www.uff.br/cdme/>. Acesso em: 03 Maio 2015.

UNESC. PIBID Educação Básica: a intertextualidade da formação docente inicial e continuada. Disponível em:<http://www.unesc.net/portal/capa/index/391/>. Acesso em:12 Maio 2015.

USISKIN, Z. Resolvendo os Dilemas Permanentes da Geometria Escolar. In: LINDQUIST M. M. e SHULTE A. P. (org) Aprendendo e Ensinando Geometria. São Paulo: Atual, 1994. p.21-39

WEISS, A.M.L.; CRUZ, M.L.R. M. A Informática e os Problemas Escolares de Aprendizagem. 3.ed. Rio de Janeiro: DP \& A, 2001. 
SC - Santa Catarina. Proposta Curricular de Santa Catarina: formação integral na educação básica. Estado de Santa Catarina, Secretaria de Estado da Educação. 2014. Disponível em: <www.propostacurricular.sed.sc.gov.br>Acesso: 03 Jun 2015. 